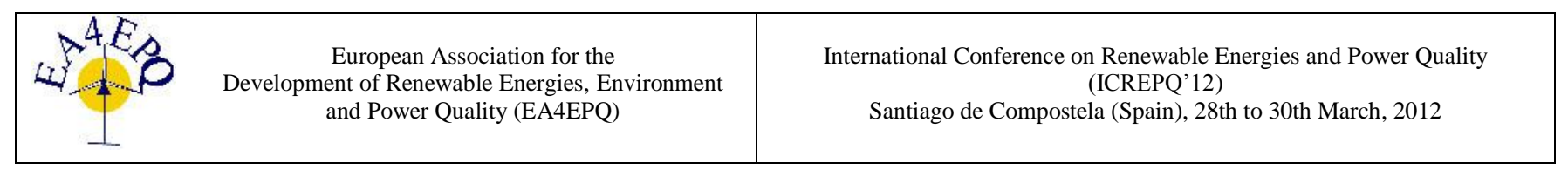

\title{
Simulating shadow effect on PV panels
}

\author{
L. Dorobantu, M.O. Popescu, Cl. Popescu, A. Craciunescu \\ Electrical Engineering Faculty \\ POLITEHNICA University of Bucharest \\ 313 Independentei, 060042 Bucharest, Romania, Tel/Fax : +040 213181003 \\ loredana.dorobantu@upb.ro; mo_popescu@ rectorat.pub.ro; claudia.popescu@upb.ro
}

\begin{abstract}
Through this paper we study losses that occur in a photovoltaic system by making simulations using the following software: Pspice and PVSYST, emphasizing the moment when the PV cells are shaded or covered, namely when the level of irradiation is not uniform throughout the module. In technical literature, the irradiation degree of solar panels is one of the determining factors for PV systems to function in optimal parameters. In this paper we modeled the effect of shading and covering of photovoltaic cells with PSpice software simulator.
\end{abstract}

\section{Key words}

renewable energy, solar cells efficiency, shadow effect, covered cells effect, PVSYST, PSpice modeling.

\section{Introduction}

The present shadow casting study on the solar surface was made on a $2 \mathrm{kWp}$ photovoltaic plant grid connected.

At first, simulations were made using the software PVSYST, which proved to be effective for analyzing various types of autonomous systems / grid connected, in combination or not with other systems that can produce energy from renewable sources.

By choosing this software, we used it's advantage that it highlights the losses arising from the PV panels shading. The software allows simulation of different scenarios, either by changing area / area affected by shading or by changing their position or obstacles, to the photovoltaic system considered. It also offers the possibility to perform calculations of losses caused by shading, animations can be achieved either by imposed scenarios in particular times or in longer periods of time set before [6].
PVSYST software provides information about the sun trajectory corresponding to location where the system is analyzed, providing information about the losses caused by shading in various periods of the year.

In the second stage for studying closely the shading phenomenon, we used circuit analysis program, PSpice, to see the effects that occur both at the cell level and panel level, in the same conditions. For this study we considered two cells connected in parallel with the same characteristics, analyzed in various conditions. For the study to be complete, we took into account the wiring of the two cells in series, so it can take into account the covering effect of the photovoltaic cells. For detailed observations of this phenomenon that occur in photovoltaic modules, we considered three scenarios for the study of the phenomenon mentioned above.

\section{PV system sizing and evaluation of losses using PVSYST software}

For our system, the chosen location was Bucharest. The software updates its weather database listed in the table in Fig.1, data that helped us to calculate all the output parameters, depending on the position of the sun during the time of the year and the angle it has during the measurements. Some very important factors for the study of photovoltaic cells are the degree of irradiation and the average temperature of the surveyed sites [1]. In the table below are displayed only monthly mean values corresponding to these parameters, so we can make a clear overview. 


\begin{tabular}{|c|c|c|c|c|}
\hline & $\begin{array}{l}\text { Global Irrad. } \\
\text { kWh/mt.mth }\end{array}$ & $\begin{array}{l}\text { Diffuse } \\
\mathrm{kWh} / \mathrm{m}^{2} . \mathrm{mth}\end{array}$ & $\begin{array}{l}\text { Temper. } \\
{ }^{\circ} \mathrm{C}\end{array}$ & $\begin{array}{l}\text { Wind Vel } \\
\mathrm{m} / \mathrm{s}\end{array}$ \\
\hline January & 41.0 & 23.0 & -1.0 & 3.20 \\
\hline February & 55.0 & 30.0 & 0.1 & 5.10 \\
\hline March & 89.0 & 48.0 & 5.6 & 4.70 \\
\hline April & 134.0 & 63.0 & 11.1 & 4.20 \\
\hline May & 168.0 & 76.0 & 16.7 & 4.10 \\
\hline June & 192.0 & 78.0 & 20.0 & 3.70 \\
\hline July & 196.0 & 77.0 & 22.2 & 3.20 \\
\hline August & 175.0 & 68.0 & 21.7 & 3.20 \\
\hline September & 122.0 & 53.0 & 17.9 & 3.70 \\
\hline October & 84.0 & 39.0 & 11.8 & 3.70 \\
\hline November & 42.0 & 24.0 & 4.5 & 3.20 \\
\hline December & 29.0 & 18.0 & 0.7 & 3.20 \\
\hline Year & 1327.0 & 597.0 & 10.9 & 3.8 \\
\hline
\end{tabular}

Fig.1. Monthly average of the most important climatic factors

Based on these data, the software determines a trajectory of the sun in the sky, which will also provide information on losses, according to Fig.2. This curve provides information on the losses that occur during the entire year, because the panels cannot provide continuous power to the same parameters. Thus in the diagram below we can see a layout of the losses of March and September in $4^{\text {th }}$ area, in February and October in $5^{\text {th }}$ area, in January and November in $6^{\text {th }}$ area, and for December in $7^{\text {th }}$ area [4].

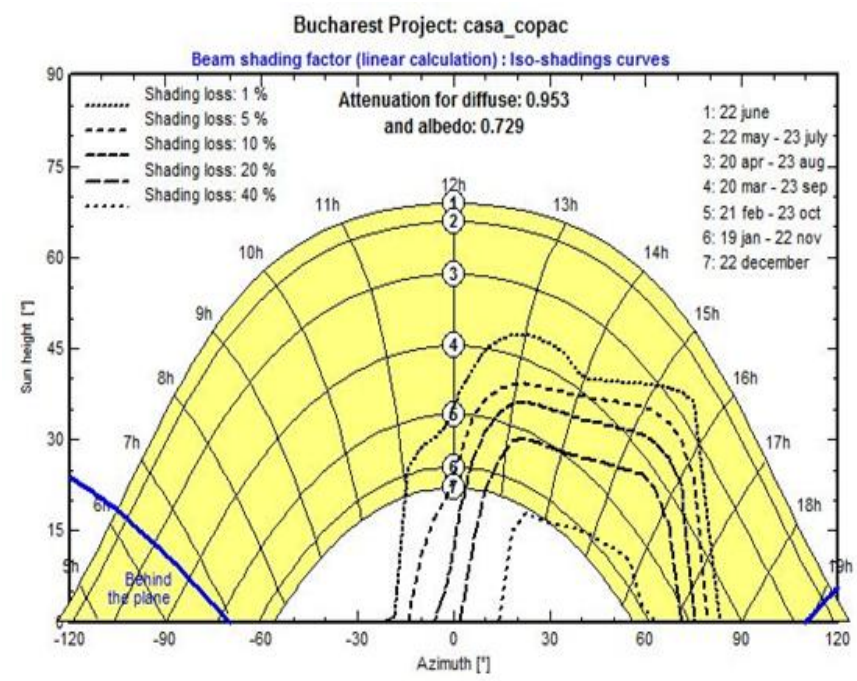

Fig. 2. Sun trajectory depending on the parameters set for Bucharest location

After establishing the geographical coordinates and characteristics of zonal factors, a very important step was the choice of components that would comprise the system itself. The software allowed the choice and setting of all components by their own library, which is up to date because of external links to manufacturers' pages. For each system principle schemas was created (Fig.3.), which are present in all main elements: the consumer, and of course photovoltaic panels inverter. Parameters were set for each user in advance [6].

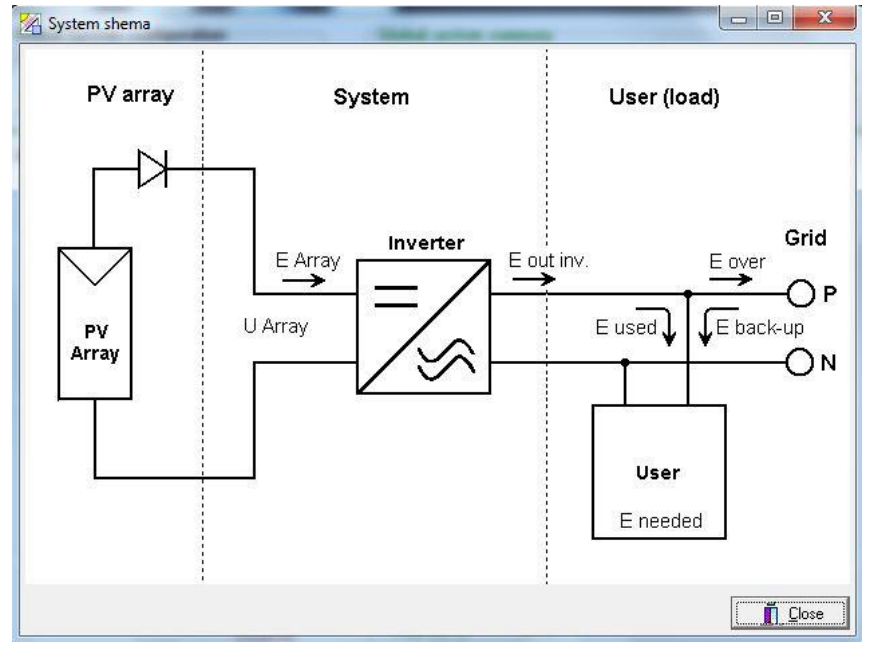

Fig.3. Schematic diagram of the PV system

From this point, we designed the model, so that we could simulate the shading phenomenon. For this, we placed an obstacle, i.e. a tree near the panels, which at different times of the day shade the panels that comprise the PV central.

PVSYST software allowed us to view the losses occurring whilst the panels are shaded. For this view, we chose February $15^{\text {th }} 2011$ to see the evolution of losses during the day. In order to calculate these losses, the data entered in the first stage, which referred to the path of the Sun in February for the analyzed case, when according to Fig.4 losses have reached $11 \%$, was taken into account.

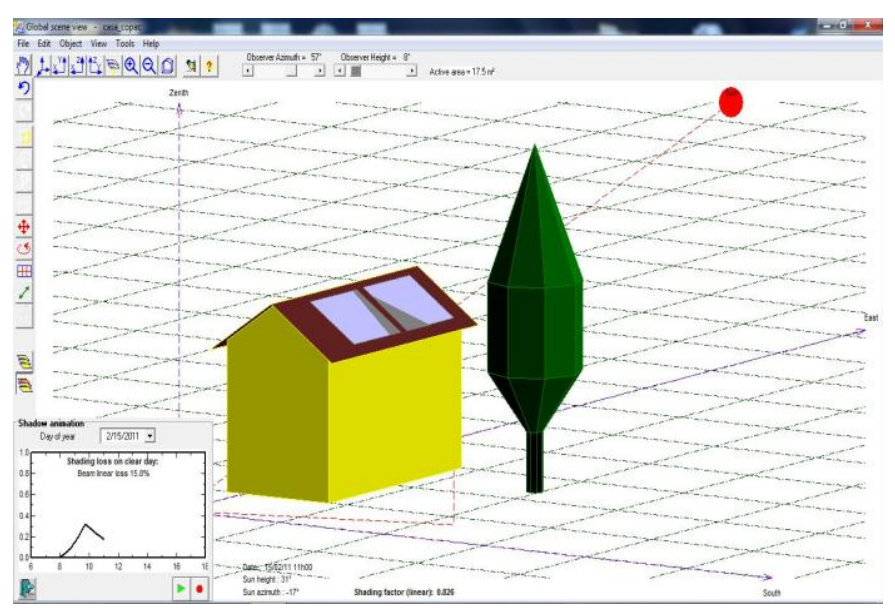

Fig.4. Image captured during simulation - on the left side of the screen you can see the evolution of losses caused by shading

Losses, regardless of their nature are very well highlighted in the report the software provides to the end of the simulation, in the following picture is shown data loss for the whole year. (Fig.5.). [6] 


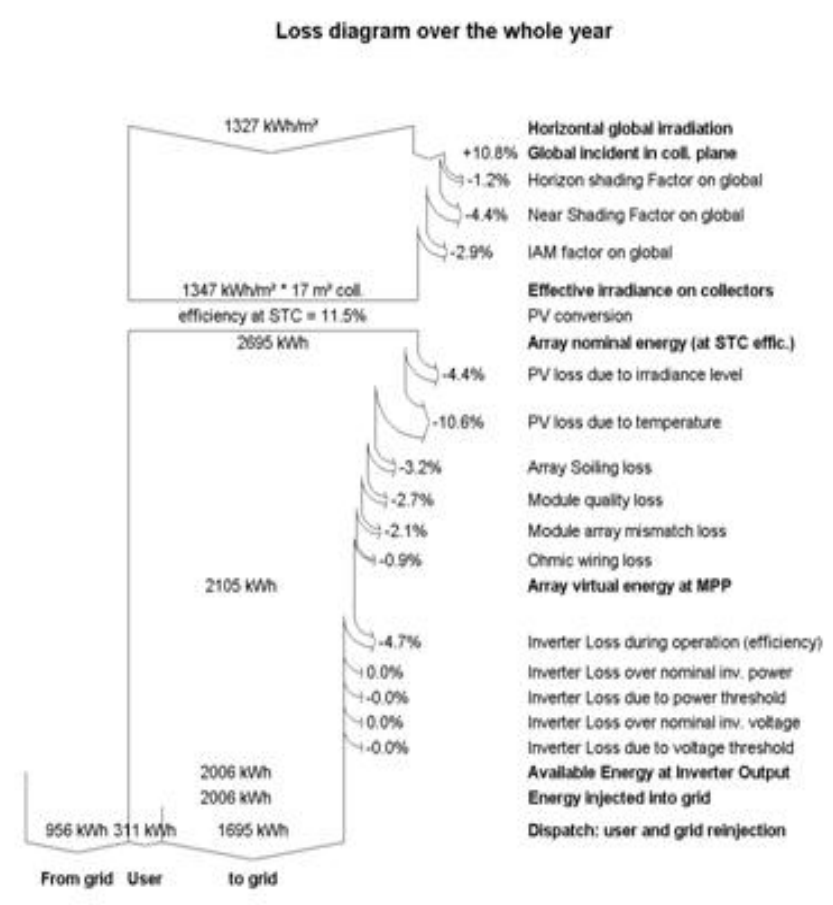

Fig.5. Corresponding diagram for a full year loss analysis system

After the quantitative evaluation of the power loss, we find it very important to better understand which are the main causes of occurrence of such loss in photovoltaic panels, specifically in the cells that make up the system, so in the second stage of analysis we used the PSpice circuit simulator to model the system in these situations.[3]

\section{Study of cells affected by shading with PSpice software}

We simulated three situations using PSpice that will be further presented, in which we used two amorphous silicon cells, similar to the composing plant modules studied previously.

\section{A. Both cells have the same degree of irradiation}

In this situation we subjected both cells in parallel, the same conditions of irradiation. We chose the brightness of $\mathrm{G}=$ $1000 \mathrm{~W} / \mathrm{m}^{2}$, this value is considered optimal by the manufacturer, for the operation of photovoltaic panels. Following the simulation seen in Fig.6, the currents through both cells are the same, and the resulting current consists of the sum of the two, reaching maximum power of $0.5 \mathrm{~A}$. Maximum power corresponding to these parameters reach somewhere around $0.2 \mathrm{~W}$.

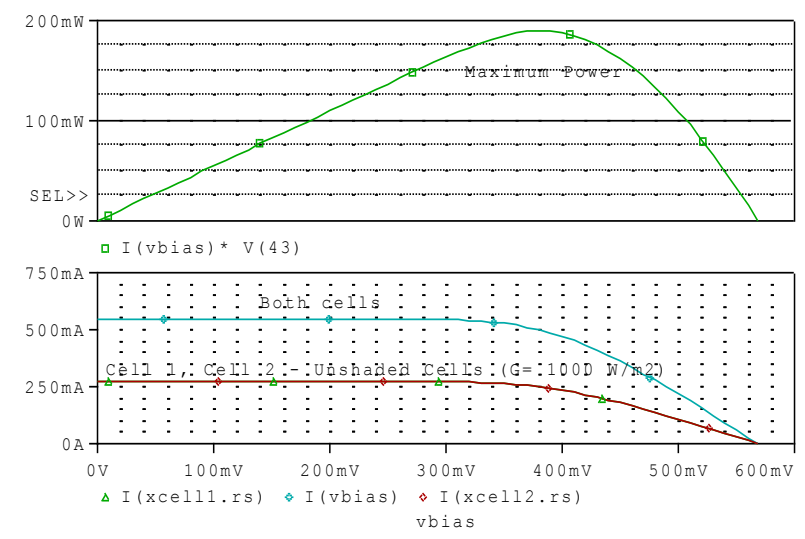

Fig.6. Currents and power values for A. scenario

\section{B. The two cells have different levels of irradiation}

In this case we analyzed the same structure, with two cells connected in parallel, but each was subjected to a new level of irradiation. Thus for one of them it has been preserved irradiation conditions of the first case, $G=1000 \mathrm{~W} / \mathrm{m}^{2}$, and for the other was applied a level of irradiation of $G=500$ $\mathrm{W} / \mathrm{m}^{2}$, equivalent to its shadowing. The simulation showed various values of currents through the two cells. For the lit cell, current value is kept at $0.25 \mathrm{~A}$, similar to the first case. Instead, the measured current on the shade affected cell decreased by half. Note that the value of the light level for shaded cell is $50 \%$ lower than in the first case. So basically the irradiation percentage decrease of light to a photovoltaic cell is very close to the percentage reduction of the current produced by the affected cell. Since the cells are connected in parallel, the total current value is lower by $25 \%$ compared to the first case presented. Default and power fell by $25 \%$, being directly proportional to the current value (Fig.7) [3].

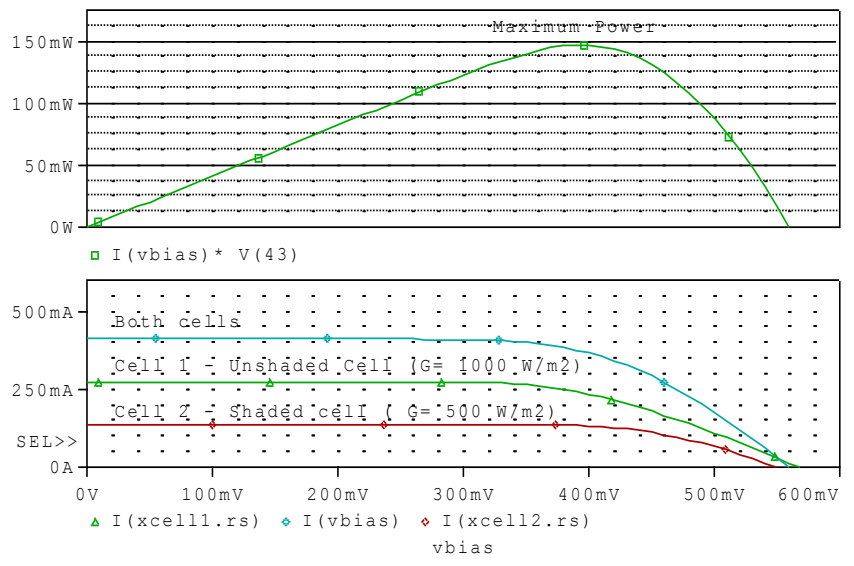

Fig.7. Current and power values for B. scenario

\section{One of the cell has optimal degree of radiation and the other has radiation zero degree}

In the latter case, we considered one of the cells in complete darkness with the brightness $\mathrm{G}=0 \mathrm{~W} / \mathrm{m}^{2}$, while the other remained in optimal conditions of irradiation. As it can be 
seen in Fig.8, the current dropped to zero, as expected, for the cell that was not illuminated. For the other cell, we kept the value of $0.25 \mathrm{~A}$, which actually gave the total amount of current through the entire structure analyzed. Maximum power value was halved in this case compared to the first situation Fig.8.
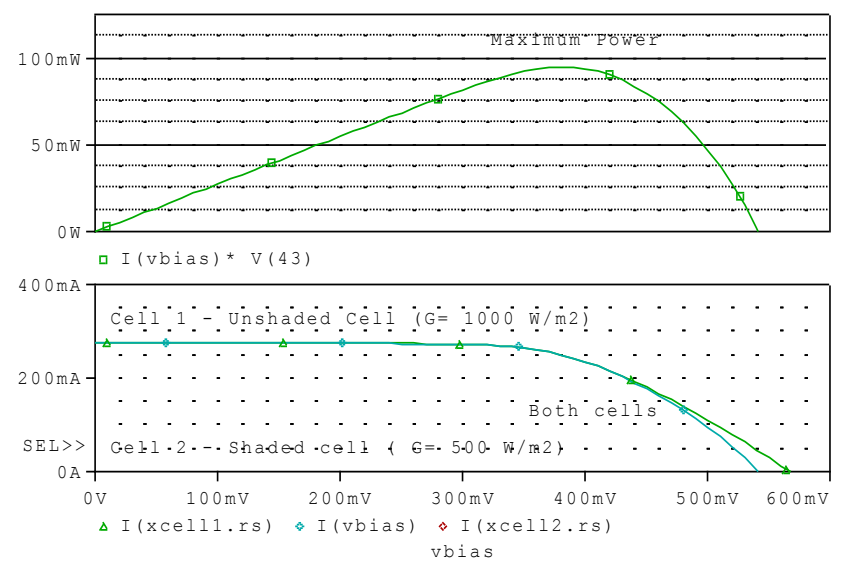

Fig.8. Current and power values for C. scenario

\section{Study of cells affected by covering with PSpice software}

In order to understand the phenomenon that occurs when the PV cells are affected by opaque layers, we put into the same conditions two PV cells wired in series.[3]

\section{Both cells have the same degree of irradiation}

The short-circuit currents values of the cells wired in series are identical, due to the same irradiance value and series and shunt resistances. Thus the total current-voltage characteristic I (V) has the same values as the short-circuit of any of the two photovoltaic cells. The total voltage values are twice the voltage drop in one PV cell.

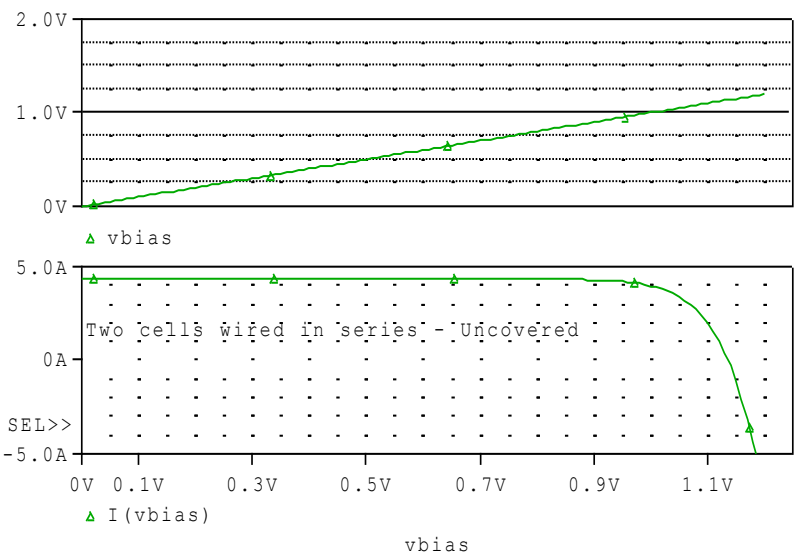

Fig.9. Current and voltage values for D scenario

\section{E. The two cells have different levels of irradiation}

The case when the cells have different levels of irradiation is a common situation (for example, the presence of dirt in one of two cells wired in series). In this case, we modified the previous net list as it follows: we considered cell number 2 with an irradiance level of $700 \mathrm{~W} / \mathrm{m}^{2}$, whereas cell number 1 receives an irradiance level of $1000 \mathrm{~W} / \mathrm{m}^{2}$. To obtain these modifications, we changed the value of the voltage source, that represents the value if irradiance in the less irradiated cell [3].

The simulation result can be seen in Fig. 11 .

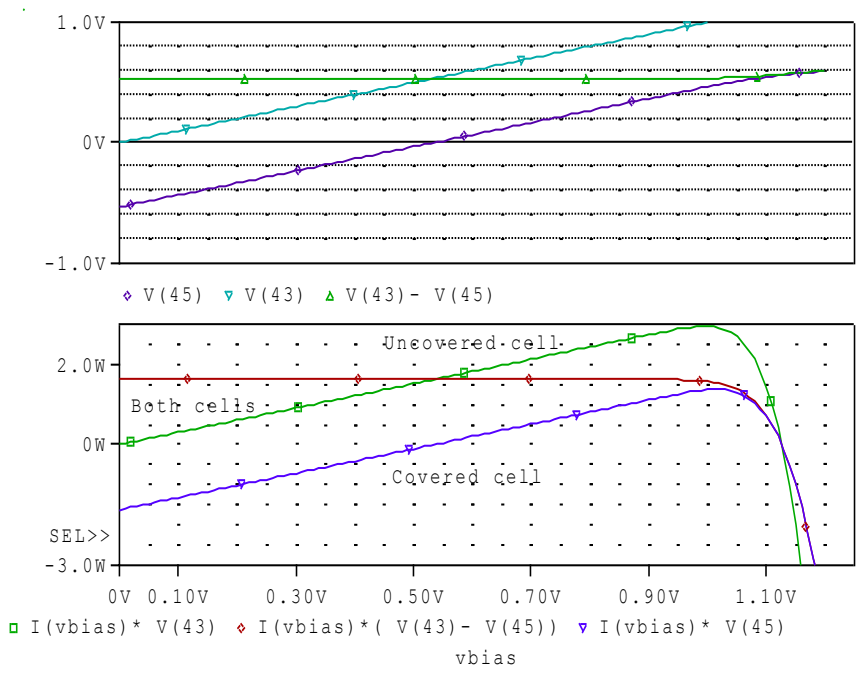

Fig.11. Voltage and power for E scenario

As seen in the Fig.11, the two PV cells wired in series, generate a short-circuit current equal to the one generated by the less irradiated cell. At this short-circuit situation, the voltage drop in the uncovered cell is $+0.53 \mathrm{~V}$, and for the covered cell is $-0.53 \mathrm{~V}$. Thus, the total voltage for the two cells wired in series is zero. The power of the two cells, in this case is $1.75 \mathrm{~W}$. So, in this case, the less irradiated cell is under reverse bias.

\section{F. One of the cell has optimal degree of radiation and the other has radiation level 10 times smaller}

The less unfortunate situation is when one of the two cells wired in series is completely covered, so the irradiation level is near to zero $\mathrm{W} / \mathrm{m}^{2}$. To observe what happened in this case, we reduced the irradiation level in cell number 2 to $100 \mathrm{~W} / \mathrm{m}^{2}$, and we obtained the results showed in Fig. 12. 


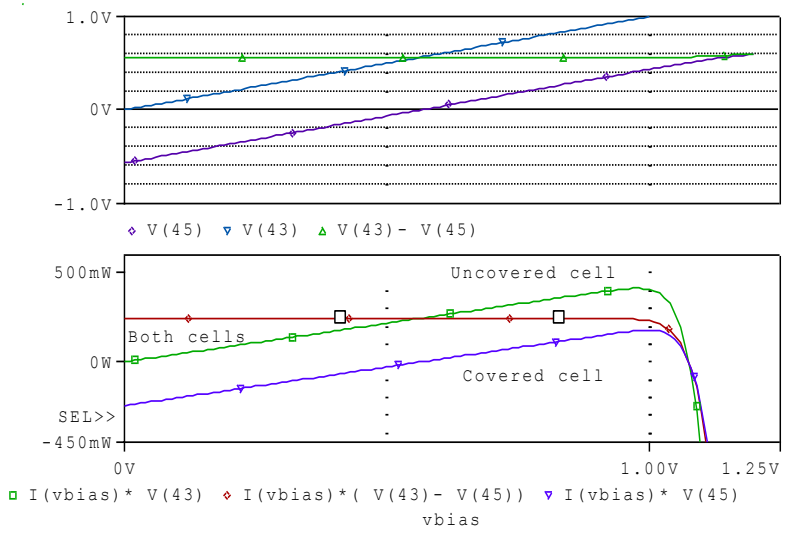

Fig.12. Voltage and power for F scenario

It can be seen that the voltage drop value is limited to $+0.53 \mathrm{~V}$ in the case of the cell under normal irradiation level, and $-0.53 \mathrm{~V}$ in case of the covered cell. The power level for the two cells drops around $0.25 \mathrm{~W}$, being 7 times smaller than in previous case, where irradiation level of the covered cell had $700 \mathrm{~W} / \mathrm{m}^{2}$.

\section{Conclusions}

By the analysis presented in this paper, we tried to highlight the losses caused by shadow casting on the surface of photovoltaic panels. At first, using the software PVSYST, we pointed out the existence of these losses throughout the day, but also for longer periods of time. It could also be observed that these losses are differentiated by the position of sun in the sky at various times of the year. And in the second stage, carrying out simulations in PSpice software, we found the source of the loss in photovoltaic systems. In the first part we took into consideration the losses that occur in PV cells wired in parallel, and in the second part we analyzed the losses in the cells wired in series. We analyzed two situations that can cause losses in PV cells: shadowing and covering of PV cells. The present study was realized for two PV cells, in order to observe clearly the phenomena that occur and their behavior. This small scale analysis can be extended for an entire PV module or a PV plant.
The two types of simulations are complementary, each having the purpose of highlighting certain aspects of the studied problem. PVSYST software detected the losses, and framed them within certain limits, for the location and the studied system. PSpice program, with the purpose to clarify the response of the studied system in various situations. By combining the two types of simulations, the effectiveness and applicability in trials that aim the study of efficiency of photovoltaic systems has been proven.

\section{Acknowledgement}

This paper is supported by the Sectoral Operational Programme Human Resources Development (SOPHRD), financed from the European Social Fund and by the Romanian Government under the contract number POSDRU/88/1.5/S/61178.

\section{References}

[1] R.A. Messenger, J.Ventre," Photovoltaic Systems Engineering", CRC Press, Florida 2004.

[2] R. Sullivan, "Shadow effects on a series-parallel array of solar cells", Greenbelt, Maryland, NASA article.

[3] S.Silvestre, L. Castaner, "Modelling photovoltaic systems using PSpice", John Wiley \& Sons Ltd, 2002

[4] http://eosweb.larc.nasa.gov

[5] http://solargis.info

[6] http://pvsyst.com 